\title{
Statistical Study For The prediction of pKa Values of Substituted Benzaldoxime Based on Quantum Chemicals Methods
}

\author{
Emad A.S. Al-Hyali*, Nezar A. Al-Azzawi, and Faiz M.H. Al-Abady ${ }^{\dagger}$ \\ Department of Chemistry, College of Education, University of Mosul, Mosul, Iraq. *E-mail: emadabd2006@yahoo.com \\ 'Department of Chemistry, College of Science, University of Tikrit, Tikrit, Iraq
}

(Received October 19, 2010; Accepted August 4, 2011)

\begin{abstract}
Multiple regression analysis was used for the calculation of pKa values of 15 substituted benzaldoximes by using various types of descriptors as parameters. These descriptors are based on quantum mechanical treatments. They were derived by employing semi-empirical calculation represented by the PM3 model and an Abinitio method expressed by Hartree-Fock $(\mathrm{HF})$ model performed at the $6-311 \mathrm{G}(\mathrm{d}, \mathrm{p})$ level of theory. The parameters tested for their ability to represent the variations observed in the experimental $\mathrm{pKa}(\mathrm{s})$ are atomic and structural properties including Muliken charges on the atoms of hydroxyl group and $\mathrm{C}=\mathrm{N}$ bond, the angle $\mathrm{C}_{6}-\mathrm{C}_{1}-\mathrm{C}_{7}$, and length of $\mathrm{O}-\mathrm{H}$ bond. Molecular properties are also used like energies of HOMO and LUMO, hardness $(\eta)$, chemical potential $(\mu)$, total energy(TE), dipole of molecule(DM), and electrophilicity index $(\mathrm{W})$. The relation between $\mathrm{pKa}$ values and each of these parameters of the studied compounds is investigated. Depending on these relations, two sets of parameters were constructed for comparison between the PM3 and HF methods. The results obtained favor the Abinitio method for such applications although both models proved to have high predictive power and have sufficient reliability to describe the effect of substituents on pKa values of benzaldoxime compounds under consideration which is clear from the values of correlation coefficient $\mathrm{R}^{2}$ obtained and the consistency between the experimental and the calculated values.
\end{abstract}

Key words: pKa value, Benzaldoxime, PM3, $A b$ initio

\section{INTRODUCTION}

Oximes are well known compounds with a general functional group $(-\mathrm{C}=\mathrm{N}-\mathrm{OH})$. They are the condensation products of hydroxyl amines with aldehydes (forming aldoxime), ketones (forming ketoxime), or quinone. The aldoxime exists only as a syn isomer, where as benzaldoxime as (aromatic aldoximes) exist in syn and anti isomers. These two geometrical isomers have very different properties.

Oximes are very important compounds. They have wide application and were used in various fields. They were used as analytical reagents. ${ }^{1}$ Cyclohexanone oxime is converted into its isomer epsilon-caprolactam which represents the raw material for the synthesis of nylon- $6 .{ }^{2}$ The amides obtained by Beckmann rearrangement can be converted into amine by hydrolysis, which could be employed as starting materials for the manufacture of dyes, plastic, fibers and pharmaceuticals.

Oximes can be used as peel-preventing additives in paints and lacquers. They act as antioxidants against oxidative drying materials which form sticky skin with air oxygen.

Another effect of anti-skinning offers drying time delay which can be used in formulating paints. Oximes are also used as chemical building block for the synthesis of agrochemicals and pharmaceuticals.

In medicine application, oxime structure is found to be effective in cholinesterase reactivators to treat the poisoning by organo-phosphates. ${ }^{3}$

Oximes are used as ligands in transition metal complex catalyst chemistry. Oxime acts as anti oxidant, radical scavenger which found applications in textile, plastic, paint, detergent, and rubber industry. They have therefore, long been the goal of many researchers in different areas of chemistry. The knowledge of pKa values provides a basis for understanding the chemical reactions between the compound of interest and pharmacological target. Additionally, they play a major role in acid-base titration, complex formation and many other analytical procedures. ${ }^{4}$ The pKa value of a compound is therefore, a very important chemical phenomenon (among others) that influences many characteristics such as its reactivity and spectral properties. Its importance lies in that such value is affected by the nature and location of substituents present on the compound. ${ }^{5}$ The pKa values are therefore sensitive to the variation of inductive effect (which may result from formal charges or dipole within a molecule) 
and steric effect that arise from spatial interaction between adjacent groups within the molecule. Since such effects can be evaluated by quantum chemical methods, ${ }^{8-11}$ certain parameters might serve as useful descriptors for understanding the physical and chemical effects of substituents on the pKa values of the benzaldoxime compounds under consideration.

In order to find how far experimental finding are reflected in theoretical predictions and what kind of information can be extracted from such investigation, the present work examines the applicability of quantum chemical parameters derived from PM3 and HF methods as descriptors for substituents effects on the pKa values of benzaldoximes. Several sets of parameters were derived for the theoretical predictive of $\mathrm{pKa}$ values by regression analysis.

\section{METHODS}

In order to determine the conformation of the lowest energy for each molecule of the fifteen benzaldoxime compounds listed in Table 1, full geometrical optimization was carried out at the level of semi-empirical PM3 methods as well as Hartree-Fock(HF) using gradient technique $^{13,14}$ and 6-311 G(d,p) basis set. At the semi- empirical PM3 level, geometries of all possible conformers were optimized, while $A b$ initio $[\mathrm{HF} / 6-311 \mathrm{G}(\mathrm{d}, \mathrm{p})]$ optimization was performed only for the most stable conformer found with PM3 method. In all cases, the completion of optimization in order to ensure obtaining geometry with minimum energy was examined.

The optimized geometries were used for evaluation of natural atomic charges and structural parameters such as total energy (TE), dipole moment (DM), Angles, O-H bond length, the highest occupied molecular orbital energy (Еномо), the lowest unoccupied molecular orbital energy ( $\left.\mathrm{E}_{\mathrm{LUmO}}\right)$. The values of $\mathrm{E}_{\text {Hомо }}$ and $\mathrm{E}_{\mathrm{LUmo}}$ were used for the calculation of other molecular properties, namely; hardness $(\eta),{ }^{15}$ chemical potential $(\mu),{ }^{16}$ and electrophilicity index (W) as illustrated in the following equation:

$$
\begin{aligned}
& \mu=\left(E_{\text {HOMO }}+E_{\text {LUMO }}\right) / 2 \\
& \eta=\left(E_{\text {HOMO }}-E_{\text {LUMO }}\right) / 2 \\
& W=\left(\mu^{2} / 2 \eta\right)
\end{aligned}
$$

The Chem. Office Program (V.11, 2008 of Cambridge Software, USA) was employed for the performance of conformational analysis and determination of final equilibrium geometries and the calculations of all the quantum chemical descriptors.

Table 1. Structure and experimental $\mathrm{pKa}$ values of the benzaldoximes considered for this study

(n)




\section{Multiple Linear Regression(MLR) ${ }^{18}$}

MLR analyses were carried out in order to correlate the experimental $\mathrm{pKa}$ values to the electronic and structural variables obtained by quantum chemical calculations. The MLR can be expressed by the following equation:

$$
\mathrm{pKa}=\mathrm{b}+\sum \mathrm{a}_{\mathrm{i}} \mathrm{x}_{\mathrm{i}}
$$

Where $b$ is a constant and represents a reference value, $x_{i}(s)$ the parameters selected for the regression and $a_{i}(s)$ the coefficients of the parameters. The MLR calculations were performed by the SPSS package V.12 for windows. The correlation coefficient (R) and standard error (SE) were utilized as an indication of the linearity and stability of the chosen model.

\section{RESULTS AND DISCUSSION}

The assessment of $\mathrm{pKa}$ values of hypothetical compounds is of prime interest. The knowledge strength of acid which required to protonate a compound is of great importance for the investigation of the kinetic and mechanism of organic reactions. ${ }^{19,20}$ The protonated fraction is also of special significance in the studies of absorption, distribution and eventual excretion of drugs, depending on the active substance which contains acidic of basic functional groups, which are ionized to varying degrees at physiological pHs. The influence of acidity constant on biological activity has been reviewed by many researcher groups. ${ }^{21-23}$

In this paper the experimental pKa values of benzaldoxime derivatives considered have been evaluated using a half integral potentiometric method. ${ }^{12}$ These values are correlated with some descriptors derived by the help of quantum chemical calculation which are basically electronic and energy related values and they are thought to be capable of describing the effect of substituents on $\mathrm{pKa}$ values successfully. The parameters used as descriptors for pKa variation in this work are derived by two methods namely, PM3 (as a semi empirical method, RMS gradient $=0.1$, Algorithm=Beeman) and HF carried out at base set [6-311 G(d,p)] as an Ab initio model.

In developing pKa models, it is reasonable to expect that variations in the pKa should be correlated in some way with the electronic charges at the dissociating positions. ${ }^{24}$ For the benzaldoximes, we found that atomic charges on the functional group heavy atoms ( $\mathrm{O}$ of the $\mathrm{OH}$ ) and the acidic hydrogen in $\mathrm{OH}$ can serve as good regression parameters. ${ }^{9-11}$ The $\mathrm{pKa}$ values of $\mathrm{OH}$ group vary with substitution, increasing with electron donating groups and decreasing with electron withdrawing groups. The substitution on the benzene ring affect the charge on the $\mathrm{C}=\mathrm{N}$ group in addition to the length of $\mathrm{O}-\mathrm{H}$ bond and determine the type of interactions that $\mathrm{OH}$ group undergoes (specially at the ortho position) which in turn affect the energy and geometry of the molecules and $\mathrm{pKa}$ value as a result.

A variety of parameters were used for the calculation of pKa theoretically. ${ }^{8,25,26}$ These parameters are based on quantum chemical methods (non of these studies used these parameters for the calculation of $\mathrm{pKa}$ of benzaldoximes) namely PM3 and HF. The Muliken partial atomic charges on the $\mathrm{H}$ and $\mathrm{O}$ atoms (of the $\mathrm{OH}$ group), $\mathrm{N}$ and $\mathrm{C}$ (of the $\mathrm{C}=\mathrm{N}$ group) are thought to correlate well to the $\mathrm{pKa}$ values of the studied compounds in spite of their shortcoming. ${ }^{26}$ The other parameters considered as descriptors for the $\mathrm{pKa}$ values and employed in this analysis are the total energy of molecule (TE), dipole of molecule (DM) and angle $\left(\mathrm{C}_{6}-\mathrm{C}_{1}-\mathrm{C}_{7}\right)$ (see the structure below):

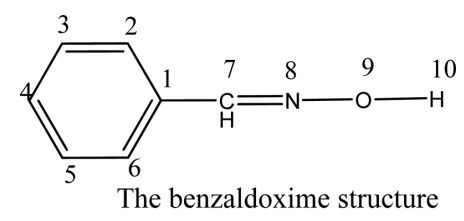

\section{The Benzaldoxime Structure}

Additional parameters were also tested such as the energy of HOMO and LUMO orbitals and the values of $\mu$, $\eta$ and $\mathrm{W}$ which are calculated as illustrated in equations (1), (2), and (3) respectively.

The values of all the mentioned descriptors calculated by PM3 and HF methods are given in Tables 2 and 3 respectively.

As a primary step, correlation among the selected parameters and the $\mathrm{pKa}$ values of the benzaldoxime compounds and among the parameters themselves are performed. The statistics results obtained for the performance of these parameters are listed in Table 4.

The correlation coefficient assumes a value between(-1) and $(+1)$. If one variable tends to increase the other decrease, the correlation coefficient is negative. Conversely, if the variables tend to increase together the correlation coefficient is positive.

The results of Table 4 show weak simple relations among the pKa values and the other parameters. As expected substituents cause changes in the electronic density at the dissociating functional groups in benzaldoximes. Good correlation among the atomic charges of the hydroxyl group $\left(\mathrm{O}_{9}\right.$ and $\left.\mathrm{H}_{10}\right)$ and the $\mathrm{C}=\mathrm{N}$ group $\left(\mathrm{C}_{7}\right.$ and $\left.\mathrm{N}_{8}\right)$ are noticed. The rela- 
Table 2. Values of descriptors calculated by PM3 method

\begin{tabular}{|c|c|c|c|c|c|c|c|c|c|c|c|c|c|}
\hline$d$ & $\begin{array}{c}\text { H10 } \\
\text { Charge }\end{array}$ & $\begin{array}{c}\text { O9 } \\
\text { Charge }\end{array}$ & $\begin{array}{c}\text { N } 8 \\
\text { Charge }\end{array}$ & $\begin{array}{c}\text { C 7 } \\
\text { Charge }\end{array}$ & $\begin{array}{c}\text { Angle } \\
\text { C6-C1-C7 }\end{array}$ & TE & DM & $\begin{array}{c}\text { O-H } \\
\text { Length (A) }\end{array}$ & $\begin{array}{c}\mathrm{E}_{\mathrm{HOMO}} \\
(\mathrm{ev})\end{array}$ & $\begin{array}{c}\text { E }_{\text {LUMO }} \\
(\mathrm{ev})\end{array}$ & $\begin{array}{c}\eta \\
(e v)\end{array}$ & $\begin{array}{c}\mu \\
(\mathrm{ev})\end{array}$ & $\begin{array}{l}\mathrm{W} \\
(\mathrm{ev})\end{array}$ \\
\hline & 0.214 & .263 & -0.020 & -0.053 & 122.581 & -4.229 & -1.159 & 0.9507 & -0.342 & -0.004 & .169 & 173 & 0.082 \\
\hline & 213 & .262 & -0.031 & -0.043 & 120.292 & & & & & -0.004 & 0 & & 0.078 \\
\hline & 21 & - & -( & -0 & 129.8 & & & 250 & & & & & 0.072 \\
\hline & 0.221 & -0.268 & 0.018 & -0.133 & 120.168 & 4.10 & -1.167 & 952 & -0.373 & -0.069 & 0.152 & -0.221 & -0.052 \\
\hline & 0.170 & -0.215 & 0.071 & -0.140 & 119.375 & -0 . & & 959 & -0.343 & -0.014 & 164 & & -0.075 \\
\hline & 173 & .218 & .065 & -0.14 & 1 & & & 57 & 1 & -0. & 2 & & -0.077 \\
\hline & 0.213 & .261 & .033 & -0.04 & 123.908 & & & 51 & -0.297 & -0.009 & 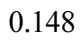 & & -0.074 \\
\hline COOL & 0.215 & -0.258 & -0.016 & -0.057 & 12 & & & 50 & 5 & -0. & 4 & & -0.070 \\
\hline 2 & 0.221 & -0.262 & -0.007 & -0.058 & 124.004 & -5. & -0 . & 0.950 & -0.372 & -0.071 & 0.150 & 21 & -0.050 \\
\hline$-F$ & 0.217 & -0.257 & -0.017 & -0.055 & 123.801 & -2.2 & -1.1 & 0.951 & -0.346 & -0.016 & 0.165 & & -0.074 \\
\hline & 0.213 & -0.260 & -0.0 & -0.0 & & & & & & & & & -0.077 \\
\hline & 0.211 & -0.263 & -0.052 & -0.024 & 12 & & & 51 & 3 & 0. & & & -0.076 \\
\hline COOU & 0.217 & -0.258 & -0.006 & -0.067 & 122.682 & -3.274 & & 50 & -0 . & -0.035 & 60 & 5 & -0.065 \\
\hline & 0.222 & -0.255 & 0.005 & -0.075 & 124.741 & & -0.5 & 0.952 & & -0. & 50 & & -0.050 \\
\hline$F_{2}$ & 0.216 & -0.259 & -0.023 & -0.048 & 124.159 & -2.284 & -1.182 & 0.951 & -0.340 & -0.023 & 0.162 & -0.185 & -0.071 \\
\hline
\end{tabular}

Table 3. Values of the descriptors used as parameters calculated by HF method

\begin{tabular}{lccccccccccccc}
\hline Compd. & H10 Charge & $\begin{array}{c}\text { O9 } \\
\text { Charge }\end{array}$ & N8 Charge & $\begin{array}{c}\text { C7 } \\
\text { Charge }\end{array}$ & $\begin{array}{c}\text { Angle } \\
\text { C6-C1-C7 }\end{array}$ & TE & DM & O-H & $\begin{array}{c}\mathrm{E}_{\text {HOMo }} \\
\text { (ev) }\end{array}$ & $\begin{array}{c}\mathrm{E}_{\text {Lumo }} \\
\text { (ev) }\end{array}$ & $\eta$ & $\mu$ & W \\
\hline B & 0.415 & -0.601 & -0.127 & 0.108 & 121.100 & -398.320 & -1.159 & 0.945 & 0.086 & -0.315 & -0.200 & -0.114 & -0.032 \\
o-OCH3 & 0.414 & -0.604 & 0.098 & 0.098 & 116.270 & -512.130 & -1.229 & 0.945 & 0.086 & -0.315 & -0.201 & -0.114 & -0.032 \\
o-NH2 & 0.411 & -0.603 & -0.206 & 0.194 & 117.380 & -453.350 & -1.305 & 0.945 & 0.096 & -0.281 & -0.188 & -0.092 & -0.022 \\
o-NO2 & 0.425 & -0.591 & -0.072 & 0.109 & 118.050 & -601.720 & -1.167 & 0.946 & 0.051 & -0.352 & -0.201 & -0.150 & -0.056 \\
o-F & 0.420 & -0.601 & -0.080 & 0.101 & 118.480 & -497.170 & 1.928 & 0.945 & 0.079 & -0.325 & -0.202 & -0.122 & -0.037 \\
m-OCH3 & 0.420 & -0.601 & -0.080 & 0.101 & 119.290 & -497.170 & 1.378 & 0.945 & 0.081 & -0.310 & -0.196 & -0.114 & -0.033 \\
m-NH2 & 0.418 & -0.596 & -0.122 & 0.106 & 119.480 & -585.880 & -1.154 & 0.943 & -0.009 & -0.297 & -0.148 & -0.148 & -0.074 \\
m-COOH & 0.421 & -0.596 & -0.122 & 0.106 & 119.480 & -585.880 & 0.642 & 0.943 & 0.048 & -0.340 & -0.194 & -0.146 & -0.055 \\
m-NO2 & 0.421 & -0.593 & -0.125 & 0.199 & 118.890 & -601.740 & -0.939 & 0.945 & 0.032 & -0.345 & -0.188 & -0.156 & -0.064 \\
m-F & 0.419 & -0.597 & -0.120 & 0.110 & 119.240 & -497.180 & -1.126 & 0.945 & 0.073 & -0.328 & -0.200 & -0.127 & -0.040 \\
p-OCH3 & 0.413 & -0.603 & -0.138 & 0.116 & 119.630 & -512.180 & -1.110 & 0.945 & 0.092 & -0.299 & -0.196 & -0.103 & -0.027 \\
p-NH2 & 0.410 & -0.606 & -0.148 & 0.119 & 119.760 & -453.350 & -1.170 & 0.944 & 0.004 & -0.293 & -0.148 & -0.144 & -0.070 \\
p-COOH & 0.420 & -0.596 & -0.113 & 0.105 & 119.410 & -585.900 & 0.632 & 0.945 & -0.035 & -0.356 & -0.160 & -0.195 & -0.119 \\
p-NO2 & 0.423 & -0.592 & -0.106 & 0.105 & 119.240 & -601.740 & -0.925 & 0.945 & -0.076 & -0.377 & -0.150 & -0.226 & -0.170 \\
p-F & 0.417 & -0.599 & -0.127 & 0.111 & 119.110 & -497.180 & -1.182 & 0.945 & -0.023 & -0.340 & -0.158 & -0.181 & -0.103 \\
\hline
\end{tabular}

tions among the atomic charges of these groups and the length of $\mathrm{O}-\mathrm{H}$ bond were also strong. Additionally, satisfactory relations are seen between charges and the dipole of the molecules. Observation of the global electrophilicity index values show that, substitution of benzaldoxime with electron acceptor group increases its electrophilic activity, while, substitution with electron donor group results in electrophilic deactivation.

Table 4 and Fig. 1 show that, the relation between the $\mathrm{pKa}$ values and the global electrophilicity index is negative slope. This is because, strong electrophilic reagent leads to low substrate selectivity in the form of low $\mathrm{pKa}$ value. According to these variations we expected to find these parameters effective in the calculation of $\mathrm{pKa}$ values statistically. The theoretical estimation of the $\mathrm{pKa}$ values of the 15 substituted benzaldoximes considered in this study based on the quantum chemical parameters as descriptors for $\mathrm{pKa}$ are carried out statistically by multiple regression analysis method.

Depending on this statistical method, two predictive models have been build up for comparison between the $A b$ initio [HF/6-311 G(d,p)] and semi empirical(PM3) methods, with the help of the variables used as descriptors and presented in Tables 2 and 3. 
Table 4. Correlation coefficients among the parameters evaluated by PM3 method

\begin{tabular}{|c|c|c|c|c|c|c|c|c|c|c|c|c|c|c|}
\hline Parameters & $\mathrm{pKa}$ & $\begin{array}{c}\text { H10 } \\
\text { Charge }\end{array}$ & $\begin{array}{c}\text { O9 } \\
\text { Charge }\end{array}$ & $\begin{array}{c}\text { N } 8 \\
\text { Charge }\end{array}$ & $\begin{array}{c}\text { C 7 } \\
\text { Charge }\end{array}$ & $\begin{array}{c}\text { C6-C1- } \\
\text { C7 }\end{array}$ & TE & DM & $\begin{array}{c}\mathrm{O}-\mathrm{H} \\
\text { Length }\end{array}$ & $\begin{array}{c}\text { E }_{\text {Номо }} \\
(\mathrm{ev})\end{array}$ & $\begin{array}{c}\text { E }_{\text {LUMO }} \\
(\mathrm{ev})\end{array}$ & $\eta$ & $\mu$ & W \\
\hline$\overline{\mathrm{pKa}}$ & 1.000 & & & & & & & & & & & & & \\
\hline H10 Charge & 0.014 & 1.000 & & & & & & & & & & & & \\
\hline O9 Charge & 0.196 & -0.931 & 1.000 & & & & & & & & & & & \\
\hline N8 Charge & -0.239 & -0.757 & 0.875 & 1.000 & & & & & & & & & & \\
\hline C7 Charge & 0.156 & 0.660 & -0.764 & -0.965 & 1.000 & & & & & & & & & \\
\hline C6-C1-C7 & 0.037 & 0.403 & -0.516 & -0.612 & 0.662 & 1.000 & & & & & & & & \\
\hline $\mathrm{TE}$ & 0.175 & -0.261 & 0.130 & 0.197 & -0.301 & -0.271 & 1.000 & & & & & & & \\
\hline DM & -0.536 & -0.798 & 0.832 & 0.776 & -0.671 & -0.420 & 0.080 & 1.000 & & & & & & \\
\hline Length O-H & -0.021 & -0.941 & 0.926 & 0.885 & -0.823 & -0.442 & 0.274 & 0.771 & 1.000 & & & & & \\
\hline $\mathrm{E}_{\text {НОмо }}$ & 0.354 & -0.140 & -0.157 & -0.497 & 0.507 & 0.424 & 0.092 & -0.193 & -0.080 & 1.000 & & & & \\
\hline $\mathrm{E}_{\text {LUMO }}$ & 0.237 & -0.340 & 0.087 & -0.304 & 0.535 & 0.154 & 0.197 & 0.034 & 0.065 & 0.857 & 1.000 & & & \\
\hline$\eta$ & -0.130 & -0.369 & 0.457 & 0.371 & -0.299 & -0.511 & 0.193 & 0.426 & 0.270 & -0.291 & 0.243 & 1.000 & & \\
\hline$\mu$ & 0.301 & -0.248 & -0.037 & -0.416 & 0.477 & 0.301 & 0.149 & -0.083 & -0.008 & 0.964 & 0.963 & -0.027 & 1.000 & \\
\hline W & -0.205 & 0.410 & -0.207 & 0.167 & -0.299 & 0.013 & -0.229 & -0.127 & -0.136 & -0.687 & -0.962 & -0.492 & -0.854 & 1.000 \\
\hline
\end{tabular}
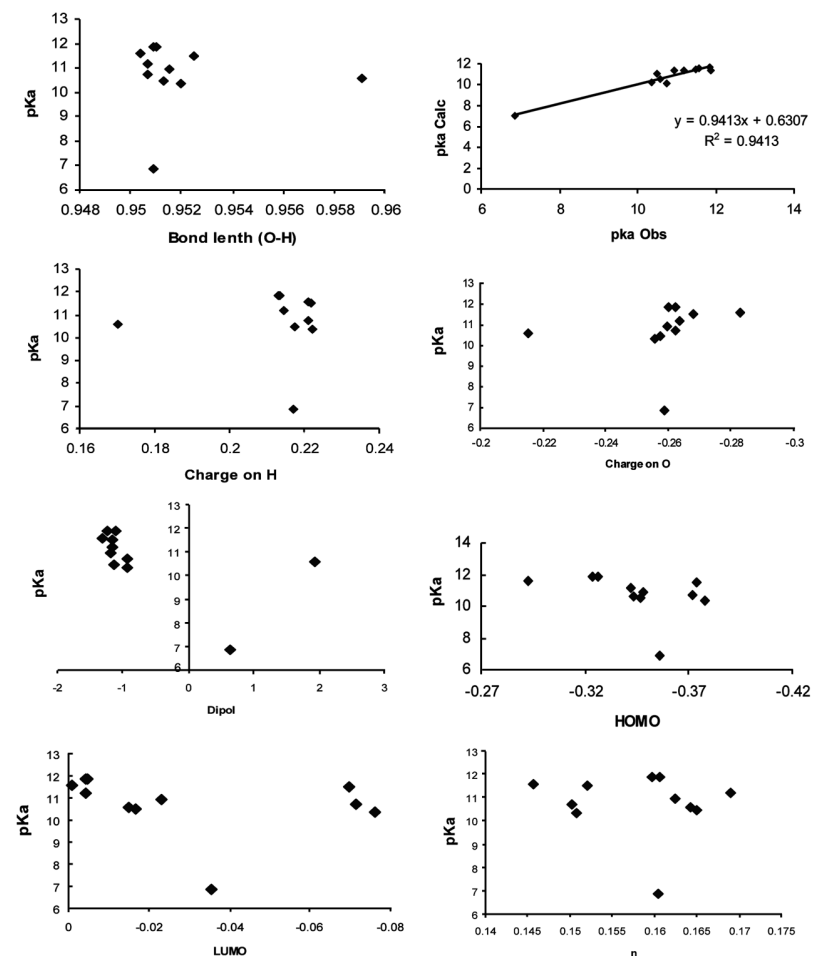

Fig. 1. Relations among pKa values and selected descriptors calculated by PM3 method (Step interval $=2.0 \mathrm{fs}$, Frame interval $=$ $10 \mathrm{fs}$, Period $=38-42$ seconds).

The first MLR model generated by variables based on the PM3 method. The results and the multiple regressions are given in Table 5.

Looking at the results of Table 5, the relation between pKa and the charges on $\mathrm{O}_{9}, \mathrm{~N}_{8}$, length of $\mathrm{O}-\mathrm{H}$ bond, and $\mathrm{DM}$ are of negative slope, which means that, the increase of the values of these descriptors increases the value of
Table 5. Summary of the regression analysis results between $\mathrm{pKa}$ values and descriptors calculated by PM3 method

\begin{tabular}{|c|c|c|c|c|}
\hline Parameter & $\mathrm{a}$ & $\mathrm{b}$ & $\mathrm{R}$ & S.E \\
\hline $\mathrm{C} 7$ & -23.59 & \multirow{2}{*}{8.825} & \multirow{2}{*}{0.325} & \multirow{2}{*}{1.468} \\
\hline N8 & -34.901 & & & \\
\hline O9 & -82.173 & \multirow{2}{*}{6.626} & \multirow{2}{*}{0.420} & \multirow{2}{*}{1.409} \\
\hline $\mathrm{H} 10$ & -80.352 & & & \\
\hline Angl & 0.195 & \multirow{2}{*}{-2.137} & \multirow{2}{*}{0.528} & \multirow{2}{*}{1.318} \\
\hline TE & 0.106 & & & \\
\hline Len O-H & -31.294 & \multirow{2}{*}{41.262} & \multirow{2}{*}{0.026} & \multirow{2}{*}{1.552} \\
\hline $\mathrm{H} 10$ & -3.503 & & & \\
\hline DM & -1.658 & \multirow{2}{*}{27.743} & \multirow{2}{*}{0.702} & \multirow{2}{*}{1.105} \\
\hline O9 & 70.192 & & & \\
\hline DM & -1.584 & \multirow{3}{*}{28.189} & \multirow{3}{*}{0.815} & \multirow{3}{*}{0.961} \\
\hline O9 & 71.080 & & & \\
\hline TE & 0.151 & & & \\
\hline DM & -2.006 & \multirow{3}{*}{-667.708} & \multirow{3}{*}{0.885} & \multirow{3}{*}{0.773} \\
\hline O9 & -7.954 & & & \\
\hline Len $\mathrm{O}-\mathrm{H}$ & 709.092 & & & \\
\hline DM & -2.247 & \multirow{4}{*}{-315.128} & \multirow{4}{*}{0.970} & \multirow{4}{*}{0.434} \\
\hline O9 & -36.785 & & & \\
\hline Len O-H & 355.361 & & & \\
\hline H10 & -109.984 & & & \\
\hline DM & -2.499 & \multirow{4}{*}{43.545} & \multirow{4}{*}{0.991} & \multirow{4}{*}{0.245} \\
\hline O9 & -47.041 & & & \\
\hline W & 47.006 & & & \\
\hline H10 & -203.749 & & & \\
\hline DM & -2.498 & \multirow{5}{*}{44.015} & & \\
\hline O9 & -45.962 & & \multirow{4}{*}{0.991} & \\
\hline W & 48.129 & & & 0.268 \\
\hline H10 & -204.321 & & & \\
\hline N8 & -0.804 & & & \\
\hline DM & -2.443 & & & \\
\hline O9 & -20.750 & & & \\
\hline N8 & 5.993 & 53226 & 0004 & 0240 \\
\hline $\mathrm{H} 10$ & -159.064 & 53.226 & 0.994 & 0.249 \\
\hline Angl & -0.046 & & & \\
\hline$\eta$ & -62.042 & & & \\
\hline
\end{tabular}


$\mathrm{pKa}$ and decrease the ionization efficiency of the molecules. The values of the coefficients of $\mathrm{O}_{9}, \mathrm{~N}_{8}$ and length of $\mathrm{O}-\mathrm{H}$ bond indicate great influence of such descriptors on pKa values, which suppose that, the withdrawing substituents increase the ionization efficiency of the molecules.

The charge on the atoms $\mathrm{C}_{7}, \mathrm{H}_{10}$, angle and TE have opposite effect on the $\mathrm{pKa}$ values. The simple correlation coefficients obtained from correlating the $\mathrm{pKa}$ values and each of these descriptors found separately are weak but was found to increase significantly in the multiple regression analysis. The results of the regression analysis of $\mathrm{pKa}$ values build up with the help of the parameters calculated by the PM3 method are summarized in Table 5. In this model we have generated various equations by employing the entire variables shown in Table 2. The best fitted equations of this class are the following two in which 4 and 6 variables are used respectively.

$$
\begin{aligned}
\mathrm{pKa}= & 43.545-2.499 \mathrm{DM}-47.041 \text { Charge of } \mathrm{O}_{9} \\
& +47.006 \mathrm{~W}-203.749 \text { charge of } \mathrm{H}_{10} \\
\mathrm{pKa}= & 53.226-2.443 \mathrm{DM}-20.750 \text { charge of } \mathrm{O}_{9} \\
& +5.993 \text { charge of } \mathrm{N}_{8}-159.064 \text { charge of } \mathrm{H}_{10} \\
& -0.046 \text { Angle }-62.042 \eta
\end{aligned}
$$

Preference is given to Eq. (5) in which less number of parameters is used to describe the substituents effect on $\mathrm{pKa}$ with negligible differences to that of 6 parameters. This model (eq. 5) includes the partial Muliken charges on the atoms of $\mathrm{OH}$ group, DM and W. these values are electronic and molecular properties and have been tested as
pKa descriptors for other types of compounds in previous studies. ${ }^{26-28}$

The values of the experimental and calculated $\mathrm{pKa}$ using (eq. 5 and 6) with comparison between the experimental and predicted values of $\mathrm{pKa}$ of the considered benzaldoximes are reported in Table 6. On the basis of the statistical quality of result, it is clear that, one can use this equation to predict the pKa values of hypothetical compounds of similar type as was done for the compounds $\mathrm{m}$ $\mathrm{OCH}_{3}, \mathrm{~m}-\mathrm{NH}_{2}, \mathrm{~m}-\mathrm{COOH}$ and $\mathrm{P}-\mathrm{NH}_{2}$ which were not included in the regression analysis.

A linear relation is obtained (with $\mathrm{R}>0.97$ ) from the plot of the experimental $\mathrm{pKa}$ versus the calculated values indicating to high prediction power and reliable method for such applications.

The second MLR model has been formed with the help of the descriptors derived by HF [6-311 G(d, p)] method. In this model, various equations have been generated (Table 7). The best fitted equations are the following two:

$$
\mathrm{pKa}=-1665.177-195.988 \text { Charge of }_{9}-2.435 \mathrm{DM}+
$$
1632.195 Length of O-H - 0.007 TE

$$
\text { pKa }=-1660.158-2.436 \mathrm{DM}-0.007 \mathrm{TE}+1637.221
$$$$
\text { Length of } \mathrm{OH}-196.374 \text { Charge of } \mathrm{O}_{9}-0.059 \mathrm{~W}
$$

Preference may be given to Eq. (8) since better correlation effect is noticed even though one more parameter (W) is used. The predicted pKa values from Eq. (7) and (8) are given in Table 8. On the basis of this model, we can also justify the validity of the selected descriptors for such applications.

Table 6. Comparison between the observed and calculated pKa values evaluated by the PM3 method

\begin{tabular}{cccccc}
\hline Compd. & Obs. pKa & Calc. pKa (Eq. 5) & ${ }^{*}$ Res & Calc.pKa (Eq. 6) & ${ }^{*}$ Res \\
\hline B & 11.195 & 11.088 & -0.017 & 11.234 & -0.039 \\
o-OCH3 & 11.858 & 12.020 & -0.162 & 11.842 & 0.016 \\
o-NH2 & 11.577 & 11.662 & -0.085 & 11.675 & -0.098 \\
o-NO2 & 11.503 & 11.451 & 0.052 & 11.417 & 0.086 \\
o-F & 10.578 & 10.594 & -0.016 & 10.611 & -0.033 \\
m-OCH3 &. & 11.369 &. & 11.332 &. \\
m-NH2 &. & 12.414 &. & 11.819 &. \\
m-COOH &. & 6.713 &. & 6.811 &. \\
m-NO2 & 10.733 & 10.677 & 0.056 & 10.796 & -0.063 \\
m-F & 10.490 & 10.673 & -0.183 & 10.676 & -0.186 \\
p-OCH3 & 11.875 & 11.482 & 0.393 & 11.398 & 0.477 \\
p-NH2 &. & 12.620 &. & 12.187 &. \\
p-COOH & 6.866 & 6.849 & 0.017 & 6.828 & 0.038 \\
p-NO2 & 10.366 & 10.379 & -0.013 & 10.306 & 0.060 \\
p-F & 10.930 & 11.032 & -0.102 & 11.194 & -0.264 \\
\hline
\end{tabular}

${ }^{*}$ Res $=$ Calc. pKa - Obs. pKa 
Table 7. Results of the regression analysis between the pKa values and parameters estimated by HF method

\begin{tabular}{|c|c|c|c|c|}
\hline Parameter & $\mathrm{a}$ & $\mathrm{b}$ & $\mathrm{R}$ & S.E \\
\hline C7 & 25.607 & \multirow{2}{*}{8.562} & \multirow{2}{*}{0.416} & \multirow{2}{*}{1.412} \\
\hline N8 & 8.057 & & & \\
\hline O9 & -2.994 & \multirow{2}{*}{55.575} & \multirow{2}{*}{0.356} & \multirow{2}{*}{1.451} \\
\hline $\mathrm{H} 10$ & -111.474 & & & \\
\hline Angl & 0.009 & \multirow{2}{*}{64.643} & \multirow{2}{*}{0.524} & \multirow{2}{*}{1.232} \\
\hline TE & -0.414 & & & \\
\hline Len O-H & -212.919 & \multirow{2}{*}{-2565.641} & \multirow{2}{*}{0.638} & \multirow{2}{*}{1.196} \\
\hline H10 & 2820.015 & & & \\
\hline H10 & -245.976 & \multirow{3}{*}{-2559.222} & \multirow{3}{*}{0.640} & \multirow{3}{*}{1.127} \\
\hline Len O-H & 2849.371 & & & \\
\hline O9 & 33.978 & & & \\
\hline C7 & -3.656 & \multirow{3}{*}{-35.898} & \multirow{3}{*}{0.924} & \multirow{3}{*}{0.636} \\
\hline O9 & -75.296 & & & \\
\hline DM & -2.335 & & & \\
\hline O9 & -158.188 & \multirow{3}{*}{-130.811} & \multirow{3}{*}{0.933} & \multirow{3}{*}{0.598} \\
\hline DM & -2.430 & & & \\
\hline H10 & 107.067 & & & \\
\hline O9 & -116.713 & \multirow{3}{*}{-1671.245} & \multirow{3}{*}{0.981} & \multirow{3}{*}{0.345} \\
\hline DM & -2.174 & & & \\
\hline Len O-H & 1703.647 & & & \\
\hline O9 & -73.368 & \multirow{4}{*}{-41.559} & & \\
\hline DM & -2.419 & & 0955 & 0.530 \\
\hline N8 & 4.553 & & 0.935 & 0.030 \\
\hline $\mathrm{H} 10$ & 16.208 & & & \\
\hline O9 & -134.270 & & & \\
\hline DM & -2.213 & -1849723 & 0982 & 0343 \\
\hline Len O-H & 1881.176 & -1849.123 & 0.982 & 0.343 \\
\hline W & -2.135 & & & \\
\hline O9 & -195.988 & & & \\
\hline DM & -2.435 & -1655177 & 0999 & 0.076 \\
\hline Len O-H & 1632.195 & $-1053.1 / 1 /$ & 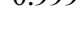 & 0.070 \\
\hline TE & -0.007 & & & \\
\hline N8 & 1.887 & & & \\
\hline O9 & -107.679 & & & \\
\hline $\mathrm{H} 10$ & 63.614 & -55.050 & 0.940 & 0.482 \\
\hline DM & -2.429 & & & \\
\hline Ang & -0.229 & & & \\
\hline $\mathrm{DM}$ & -2.436 & & & \\
\hline TE & -0.007 & & & \\
\hline Len O-H & 1637.221 & -1660.158 & 0.999 & 0.0837 \\
\hline $\mathrm{O}$ & -196.374 & & & \\
\hline W & -0.059 & & & \\
\hline
\end{tabular}

A linear relationship (Fig. 2) is obtained from the plot of the experimental $\mathrm{pKa}$ against the calculated values with high correlation coefficient $(\mathrm{R}>0.99)$. A final conclusion can be driven in which, the comparison between the $A b$ initio $[\mathrm{HF} / 6-311 \mathrm{G}(\mathrm{d}, \mathrm{p})]$ and the semi empirical(PM3) indicates reasonable correspondence between the two methods. Both of them gave high correlation coefficients and acceptable deviation.
Table 8. Comparison between the observed and calculated $\mathrm{pKa}$ values estimated by the HF method

\begin{tabular}{cccccc}
\hline Compd. & Obs. pKa & $\begin{array}{c}\text { Calc. pKa } \\
\text { (Eq. 8) }\end{array}$ & *Res & $\begin{array}{c}\text { Calc. pKa } \\
\text { (Eq. 7) }\end{array}$ & ${ }^{*}$ Res \\
\hline B & 11.195 & 11.167 & -0.027 & 11.097 & $0.098-$ \\
o-OCH3 & 11.858 & 11.841 & -0.016 & 11.669 & $0.189-$ \\
o-NH2 & 11.577 & 11.599 & 0.022 & 11.419 & -0.158 \\
o-NO2 & 11.503 & 11.563 & 0.060 & 11.400 & -0.103 \\
o-F & 10.578 & 10.509 & -0.068 & 10.377 & -0.201 \\
m-OCH3 &. & 12.332 &. & 12.255 &. \\
m-NH2 &. & 9.225 &. & 9.029 &. \\
m-COOH &. & 4.885 &. & 4.654 &. \\
m-NO2 & 10.733 & 10.675 & -0.057 & 10.517 & -0.216 \\
m-F & 10.490 & 10.527 & 0.037 & 10.367 & -0.123 \\
p-OCH3 & 11.875 & 11.924 & 0.049 & 11.853 & -0.022 \\
p-NH2 &. & 10.514 &. & 10.397 &. \\
p-COOH & 6.866 & 6.903 & 0.037 & 6.751 & -0.115 \\
p-NO2 & 10.366 & 10.327 & -0.038 & 10.161 & -0.205 \\
p-F & 10.930 & 10.995 & 0.065 & 10.854 & -0.076 \\
\hline Res $-\mathrm{Cac}$ & $\mathrm{p}-\mathrm{Obs}$ & & & &
\end{tabular}

*Res $=$ Calc. $\mathrm{pKa}-$ Obs. $\mathrm{pKa}$
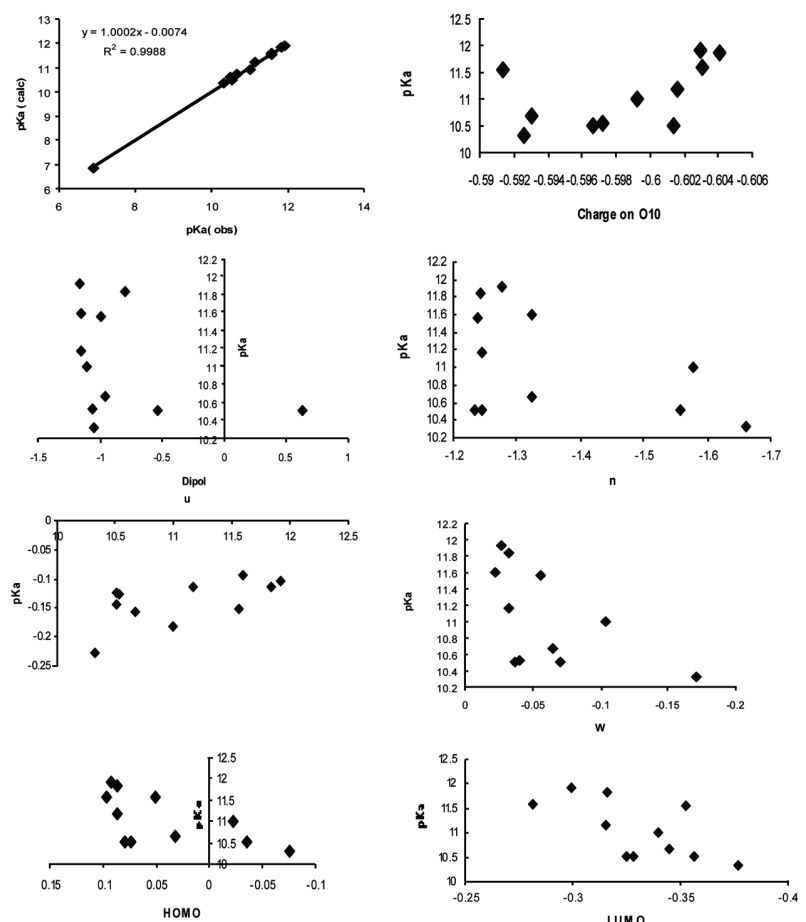

Fig. 2. Relations among $\mathrm{pKa}$ values and selected descriptors calculated by HF method (Step interval $=2.0 \mathrm{fs}$, Frame interval $=$ $10 \mathrm{fs}$, Period $=12.5-13.5$ minutes).

\section{CONCLUSION}

The predictive powers of a semi empirical(PM3) and $a b$ initi (HF) methods have been successfully conducted for the determination of the substituents effect on the $\mathrm{pKa}$ val- 
ues of benzaldoxime compounds relying on some molecular properties derived from each of them.

Several sets of parameters are obtained by employing multiple regression analysis for both methods. The best set of parameters obtained from the statistical analysis of PM3 data is represented by the Muliken charge on atoms of $\mathrm{OH}$ group, $\mathrm{DM}$ of the molecule, and $\mathrm{W}$. Where as the best set of parameters derived from the HF method included the DM, TE, length of $\mathrm{O}-\mathrm{H}$ bond, charge on $\mathrm{O}$ atom, and $\mathrm{W}$.

Both models were successfully applied for the prediction of $\mathrm{pKa}$ values of the studied compounds, although, better correlation effect is noticed in the HF method. The method used in this research could be used for the theoretical determination of $\mathrm{pKa}$ values for other family of organic compounds.

\section{REFERENCES}

1. Hdzbecher, Z.; Divis, L.; Kral, M.; Sucha, L.; Vlacil, F. Hand book of organic reagents in inorganic analysis, John Wiley \& Sons: 1976; p 691.

2. Jhaveri, L. C.; Nalk, H. B. J. Indian Chem. Soc. 1978, 2(2), 183.

3. Vavaprasad, D. M. J. Poly. Sci. Part A. Polymer Chemistry 1986, 24, 3279.

4. Ebead, Y. H.; Salman, H. M.; Abdellah, M. A. Bull. Korean Chem. Soc. 2010, 31(4), 850.

5. Lowry, T. H.; Richardson, K. S. Mechanism and Theory in Organic Chemistry, 3rd. ed.; Harper Collins; New York, 1987.

6. Pine, S. H.; Hendrickson, J. B.; Carm, D. J.; Hammond, G. S. Organic chemistry, 4th ed.; McGraw-Hill: London, 1981; p 196.

7. Strietwieser, A.; Heathcock, Jr. C. H. Introduction to Organic Chemistry, 2nd ed.; Macmillan Publishing Co.: New York, 1981; p 60.

8. Kross, K. C.; Seybold, P. G.; Peralta-Inga, Z.; Politzer, P. J. Org. Chem. 2001, 66, 6919.
9. Kross, K. C.; Seybold, P. G. Int. J. Quantum Chem. 2000, 80, 1107.

10. Gross, K. C.; Seybold, P. G.; Hadad, C. M. Int. J. Quantum Chem. 2002, 90, 445.

11. Gross, K. C.; Seybold, P. G. Int. J. Quantum Chem. 2001, $85,569$.

12. Al-Azzawi, Nezar, A. The role of hydrogen bonding and other parameters on ionization constants of benzaldoximes, Ph. D. Thesis, Mosul, Iraq. 1998.

13. Schlegel, H. B. ed.; Molar electronic structure, theory, geometry optimization on potential energy surface; World Scientific: Singapore, 1994.

14. Baker, J. J. Comput. Chem. 1986, 17, 385.

15. Parr, R. G.; Pearson, R. G. J. Am. Chem. Soc. 1983, 105, 7512 .

16. Iczkowski, R. P.; Margrave, J. L. J. Am. Chem. Soc. 1961, 83, 3547.

17. Parr, R. G.; Szentpaly, L. V.; Lin, S. J. Am. Chem. Soc. 1999, 121, 1922.

18. Shorter, J. Correlation analysis of organic chemistry; Research studies Press: New York, 1982.

19. Rochester, C. H. Acidity function; Academic Press: London, 1970.

20. Liler, M. Reaction mechanisms in aulfuric acid and other strong acid media; Academic Press: London, 1970.

21. Albert, A. Selective toxicity; Methuen, London, 1968.

22. Bieger, D.; Wassermann, O. J. Pharm. Pharmacol. 1967, $19,844$.

23. Albert, A. Selective toxicity, 6th ed.; Chapman and Hall London, Methuen, New York, 1979.

24. Park, J. M.; No, K. T.; Jhon, M. S.; Scheraga, H. A. J. Compud. Chem. 1993, 14, 1482.

25. Ibrahim, A. A.; Abdalrazaq, E. A. Am. J. Appli. Sci. 2009, K6(7), 1385.

26. Hollingsworth, C. A. Seybold, P. G.; Hadad, C. M. In. J. of Quantum Chem. 2002, 90, 1396.

27. Singh, P. P.; Srivastava, H. K.; Pasha, F. A. Bio. Org. Med. Chem. 2004, 12(1), 171.

28. Pasha, F. A.; Srivastava, H. K.; Singh, P. P. Int. J. Quantum Chem. 2005, 104(1), 87. 